THURSDAY, AUGUST 11, r88

\section{VIVISECTION AND MEDICINE}

$\mathrm{T}$ International Medical Congress which has met in London during the past week is the largest that the world has ever seen. Medical men lwave assembled from every part of the earth, and their meetings seem to have been productive of general satisfection. The objects of such a 'Congress are twofold-first, to tell or hear of new discoweries; and, second, to make men personally acquainted who have previously:been known to each ather only through their works. The latter is perhaps the more important of the two, for it is not only a source of very great pleasure, but of great profit, inasmach as it enables men to form a juster appreciation of the workers in each department of medicine, and to avoid falling into the error, very common at the present day, of placing the observations and opinions of a mere tyro on a level with those of the scientific veteran. The work of the Congress has been divided into no less than frfteen sections, each of which bas taken up some special department of the science or practice of medicine. For medioine is mow not merely an art. It is no longer practised thy simple rule-ofthumb. It is becoming, to some extent, a science, and exact knowledge is beginning to supplant blindempiricism. The nieans by which this change has been effected have been admirably illustrated in the addresses of Prof. Virchow, Mr. Simon, and Prof. Fraser.

They are those of experiment

It is by experiment alone that we are able to distinguish between facts and fancies, between the ideas which arise in men's minds and the realities of the external world. It is in proportion as we bring our ideas into accordance with facts, or, in other words, as we know instead of supposing, that onr power increases. Suppositions hawe been the bête noire of medioine. They have constantly misled men as to the causes, the nature, and the treatment of disease, and so long as they were not subjected to the test of experiment one supposition succeeded another, only to be itself replaced by a third, no less fanciful and no less delusive. This is the reason why the progreas of medicine was formerly so slow, and it is only of recent years, since the experimental mrethod has been employed, that medical knowledge has begun to acquire any exactitude. As Prof, Virchow points out in his address, the principle of modern medicine is localisation. We localise the causes and seats of a disease, we localise the action of remedies, and thus we are able to aot with certainty so far as our knowledge will carry us. If we were able to localise certainly and define accurately the causes and seats of disease and the action of our remedies, we should possess a power to arrest or prevent disease which would render death by old age the usual, instead of as at present the exceptional, termination of human life. The experiments by which exact knowledge is obtained are, as Mr. Simon points out in his address, of two kinds. "On the one hand we have the carefully pre-arranged and comparatively few experiments which are done by us in our pathological laboratories, and for the most part on other animals than man; on the other hand, we have the experiments which Vor. Xxiv.-No. 615 accident does for us, ant, above all, the incalculably large amount of crude experiment which is popularly done by man on man under our present ordinary conditions of social life, and which gives us its results for our interpretation." As an example of these two kinds of experiment, Mr. Simon quotes the classical experiments to which we habitually refer when we think of guarding against the danger of Asiatic cholera: "On the one side there are the well-known scientific infection experiments of Prof. Thiersch, and others following him, performed on a certain number of mice; on the other hand, there are the equally well-known popular experiments which, during our two cholera epidemics of $1848-49$ and $1853-54$, were performed on half a million of human beings, dwelling in the southern districts of London, by certain commercial companies which supplicl those districts with water."

Popular experiments on the causes of disease are performed everywhere around us. Even when no epidemic prevails, our hospitals are crowded with the sidk and dying, and many, very many, of these are dying from lack of knowledge. Probably the most dreaded scourge of this country is pulmonary consumption, or tubercle, as it is semetimes shortly termed, from a pathological product found in the lungs in this disease. This fearful malady seems often to attack the most beautiful and the most gifted. We have hospitals established especially for its treatment, and these institutions are crowded to the door, applicants having to wait weeks, perhaps months, before they can obtain admission. Hitherto we have been accustomed to regard this dreadful disease as one which we had no power to guard against, and whose attacks were no more to be averted than the stroke of a thunderbolt. But increased knowledge has already shown us how to avoid or prevent to a great extent the danger which we might otherwise incur from the lightning-flash, and increased knowledge is now showing us the causes which may induce consumption, and thus teaching us how to avord them. By experiment upon animals we are learning the nature of the morbid processes which occur in this disease, and the conditions which give rise to them. We are learning that tuberculosis in cows may be communicated to healthy animals fed upon the milk which they yield, and that tubercular disease may also be induced by tubercular matter inhaled in the air or conveyed into the stomach. In these experiments upon animals we are simply repeating in a scientific way the popular experiments which men daily make in blind ignorance upon men. We communicate to a few animals a disease of which men perish by thousands, and by the sacrifice of a few dogs or rabbits we gain knowledge which may enable us to preserve the lives of thousands of men, and avert the anguish which their untimely death would cause to their relations.

In the out-patient departments of our general hospitals there are probably no cases more trying to the humane physician than the cases of consumption which be sees. Racked by cough and worn to a shadow as they often are, the physician knows that he can do but little for them if they are admitted. The utmost that his art is capable of is somewhat to alleviate their sufferings, and perhaps slightly to prolong a comparatively useless life. For these reasons he is often obliged to sacrifice his own feelings, and to refuse admission to the sufferer, 
knowing that such an act of apparent charity would be real cruelty to others. By putting out of sight for a moment the fact that the number of beds in the hospitals is necessarily limited, and admitting such a consumptive patient, he would gratify his own feelings of kindness and benevolence, but would also exclude the young and strong who suffer from such acute diseases as inflammation of the heart, lungs, or kidneys, diseases which by proper care and attention in the hospital might, and very probably would, rapidly run a favourable course, and result in the patient's restoration to his family in health and strength, but which if left to themselves might damage the constitution of the sufferer and make him a burden on society, or quickly carry him off, leaving his wife a widow and his children fatherless. Although the wistful looks and earnest entreaties of the consumptive patient might lead some few morbidly sensitive and unreflecting persons to open the gate of the hospital to him rather than to the strongly-built and apathetic labourer whose life was in hourly peril from acute disease, yet most people would, in all probability, have little difficulty in deciding between the two cases, were they to apply for admission at the same time. But the case is different when the consumptive is refused, not because the other is already there, but because we know that in the ordinary course of events he must needs come. Here we are forced to disregard the promptings of sympathy with the case before us, and to do that which gives us present pain in order that we may achieve a higher though future good.

Now what occurs daily in the treatment of patients in hospitals, occurs also in the investigation of disease. In order to prevent the suffering, misery, and death of human beings, it is necessary that animals should be sacrificed, and that we should not allow ourselves, for the momentary gratification of those sentimental feelings which would lead us to avoid inflicting even slight and transitory pain upon animals, to neglect the acquirement of that knowledge which will be productive of lasting and widespread benefit to mankind. Many of those consumptive patients probably owe their weary days, their sleepless nights, and their shortened lives to popular experiments, experiments which have been made upon them just as they might have been made upon animals in the laboratory; but they have been made for a different purpose, for the purpose of gain-gain of money, and not of knowledge. These patients may have been supplied with milk from tubercular cows, because it was more profitable for the owners of the dairy to continue milking such animals than to destroy them. Such popular experiments may be carried on for many years without leading to any knowledge of their results, because the conditions under which their subjects live are so complex that it is very hard to ascertain which one of them is the cause of disease. And all this time the unfortunate sufferers from such experiments are suffering and dying for lack of the knowledge which might be acquired by a few experiments on animals in a laboratory. For in experiments $\mathrm{n}$ the laboratory the conditions are much more simple, and it is by such experiments on a small number of animals, instead of on an enormous number of human beings, that it has been ascertained that the milk of tuberculous animals is dangerous, and that the seeds of tubercle may be sown in the organism by its use. By similar experiments on a small number of animals in the laboratory we are now learning that many diseases are due to minute organisms, which we can cultivate at will under definite conditions, ascertaining their mode of growth and the influences which modify it. By such experiments M. Pasteur and others have found that these organisms may have their virulence so modified that they can be inoculated harmlessly, and that these inoculations will protect the animal against the virulent form, just as vaccination will protect against small-pox. It is only by an accurate knowledge of the causes of disease that we can hope to prevent its occurrence, and it is only by an accurate knowledge of its nature and seat, and of the action of drugs, that we can hope to cure it when it is present. The seat of disease may be determined without experiment upon animals, for, after the death of the patient, a post-mortem examination will show what parts of the body have been affected. But the alterations which we find in the dead body are only the results of disease. They are no more the disease itself than a field strewn with slain is a battle. As Prof. Virchow remarks in his address, disease presupposes life. In the dead body there is no disease; with death, life and disease disappear simultaneously. It is only in the living body that we can investigate the process of disease, and it is by experiments upon living animals that such exact knowledge of disease as we already possess has been acquired. Without the aid of experiment we are able to ascertain even less regarding the action of drugs than regarding disease, for the most powerful drugs will profoundly alter all the functions of life, and may, indeed, kill almost as rapidly as the lightning-flash, without leaving any visible trace behind to guide us to the seat of action. It is only by experiment upon living creatures that we can ascertain the action of a drug. Formerly, physicians were accustomed to make these experiments upon their patients, "pouring," as Voltaire has said, "drugs of which they knew little into bodies of which they knew less." Nor could they do otherwise. They were called upon to render assistance to their patients, and in their ignorance they did what they could; but instead of being guided by the lamp of knowledge, they followed the ignis fatuus of their own imaginations. As Prof. Fraser points out in his address before the Section of Pharmacology, fanciful resemblances between medicines and parts of the body, healthy or diseased, were supposed to show the organs which the medicines particularly affected, and the diseases in which they would be useful. For example, the white spots on the leaf of a plant were supposed to indicate that it would be useful in consumption, because in that disease white spots are found in the lungs. The carrot was employed in jaundice, because the plant and the patient were alike-yellow; and fruits were given in diseases of the heart or kidneys for no better reason than that they resembled these organs in shape. We now laugh at the wildness of these fancies, but we are justified in doing so only because they have been proved by experiment to be foolish. The experiments which proved this have mostly been made by giving drugs to large numbers of human beings, patient after patient being treated in the same way, until the inefficacy of the drug became so apparent that its use was finally abandoned. But while physicians 
were thus blindly groping after the truth, their patients were suffering or dying. The doctors might think, perhaps, that some other treatment would have been more beneficial than the one they adopted, but they did not know it, and they were obliged to act according to the best of their belief. They were forced? by the circumstances in which they were placed to perform what Mr. Simon terms a "popular" experiment instead of a scientific one, and the complicated conditions under which it was performed rendered it doubtful how much of the result was due to the drug and how much to the disease, so that a conclusion could only be arrived at after an immense number of trials. The method by which pharmacology is now studied is entirely different. Instead of first giving the medicine to a patient labouring under disease, the effect of any new drug is tested upon plants, such as algæ and fungi, and upon the lower animals, such as frogs and rabbits, and its mode of action is then exactly ascertained by means of experiment upon animals, so that before giving it to a human being we not only know what organs and structures in his body will be affected by it, but, to a great extent, how they will be affected, and consequently what changes will be produced in the course of the disease for which we administer it. Instead, therefore, of acting blindfold, we are able, almost with certainty, to relieve where we should formerly have been powerless, and to prevent suffering even when we cannot save life. The key-note of the present medical congress, struck by Prof. Virchow in his address, is the absolute necessity of experimentation upon living beings for the progress of medical science. Without experiment we can have no certain knowledge, and without knowledge we have no power to cure and prevent disease and death. Experiment there must be, and the only question is, Upon what living beings are the experiments to be performed, and how are they to be performed? Are they to be popular experiments, such as those to which $\mathrm{Mr}$. Simon alludes, blindly made upon bundreds or thousands of human beings, healthy or diseased, or are they to be made upon a few animals in laboratories? The idea of inflicting pain upon animals is naturally repugnant to every well-regulated mind, and the thought that they are preventing unnecessary suffering is probably one of the greatest pleasures that tender-hearted and sensitive persons can experience. But this pleasure may be purchased too dearly, and by preventing the infliction of a certain amount of suffering upon a few animals a much greater amount of suffering may be caused to thousands of men.

Vivid pictures have been drawn of the suffering of animals in a physiological laboratory, and, misled by these, great numbers of people have been induced to join in the agitation, and consequent legislation, against vivisection, forgetting entirely that the pain inflicted in a vivisection experiment, except in the very rarest instances, is far exceeded, both in intensity and duration, by the sufferings of very many human beings in the course of a mortal disease, and of almost all animals except those slaughtered by man or killed and eaten by other animals. Every winter hundreds and thousands of birds and beasts die of cold and hunger, and hunger and thirst must almost always hasten the death of all wild animals. Sometimes they starve simply because no food is to be obtained; but the result is the same if weakness or disease renders them unable to reach it, although it may be plentiful around them. For while the death-beds of men are usually soothed by the kindness of the friends who moisten the parched lips and administer such nourishment as the sufferer can take, animals dying from old age, weakness, or disease have no such alleviations to their sufferings. The experiments of Chossat on starvation are generally quoted as the most cruel ever performed in a physiological laboratory, and yet they were only repetitions, on an exceedingly small scale, of the experiments which are constantly being performed by the conditions of life on thousands or millions of wild animals throughout the world. The animals on which Chossat experimented did not suffer more pain than those which die in the fields or forests because their death was witnessed by an observer who utilised it to gain knowledge of great importance to man, while the sufferings of their wild companions were unseen by any human eye. Yet many people seem to think that this is the case, and that the mere fact that pain is inflicted for a beneficial purpose renders it much less endurable than if it were simply inflicted thoughtlessly or in sport. More pain is caused by the whip of a London cab-driver in one day than is inflicted in any physiological laboratory in this country in the course of weeks; and the householder who puts down a pot of phosphorous paste to poison the rats which plague him inflicts upon them a more painful death than any they would be likely to suffer at the hands of a vivisectionist. Within the last few years those who experiment upon animals have been frequently and unjustly abused for their endeavours to gain the knowledge necessary to relieve pain and cure disease. They have, however, followed the example of their great master, Harvey, who held that to "return evil-speaking with evil-speaking" was "unworthy in a philosopher and searcher after truth," and have, like him, believed that they "would do better and more advisedly to meet so many indications of ill-breeding with the light of faithful and conclusive observation." They have, indeed, submitted to legislation which was felt to be unjust, inasmuch as it was directed against abuses which were not shown to exist, and which has already been found to hamper greatly the progress of experimental investigation in this country. Confident in their sense of the necessity for experiment, and feeling assured that ere long every one capable of forming a correct opinion and willing to take the trouble of ascertaining the facts for himself would perceive the necessity, they have remained silent, though assailed, like Harvey, with opprobrious epithets. Now, however, when the opponents of vivisection are exerting all their efforts to render legislation, already sufficiently oppressive, entirely prohibitory, the medical profession has spoken out, and with no uncertain voice, and has declared that experiments upon animals are absolutely necessary. Nor could medical men do otherwise. For no man can practise the medical profession without having occasionally to suffer most acutely on account of the imperfection of his knowledge. Often and often is his heart saddened by his patient's asking, with feeble voice and wistful eye, for the relief which he is powerless to give, and again and again has he to avert his face and to shake his head when, with agonised voices, the friends around the dying sufferer cry to him, " $\mathrm{Oh}$, doctor, can nothing more 
be done?" He sees his patients dying around him for lack of the knowledge which can only be obtained by experiment, and cannot but demand that the right to perform such experiments should be conceded to those who have qualified themselves for the task. There are those who say that, instead of trying experiments on the lower animals, medical men should experiment upon thentselves; but, as Prof. Virchow points ont, "Medical men are already more exposed in epidemics of all kinds in the performance of their duties in hospitals, in the country, in their nocturnal visits to the sick, in operations and necropsies, than any other class of the community as a rule; and it requires all the blindness of the animal fanatics to require also of them that they should test on their own bodies the remedial, or poisonous, or indifferent action of unknown substances, or that they should determine the limit of permissible doses by observations made on themselves." Nor is this all. Medical men do make experiments upon themselves, and some have sacrificed their own lives in such experiments. But such a method of observation is open to the objection that the sacrifice is to a great extent useless, as the death of the experimenter deprives him of the opportunity of recording the results of his experiment. Not only has the necessity for experimentation upon animals been clearly pointed out in the addresses delivered at the Congress, but this International Medical Congress itself, the greatest assembly of men qualified to judge in the matter that has ever been held, has expressed its judgment in the resolution passed, without a single dissentient, at its concluding general meeting :-

"That this Congress records its conviction that experiments on living animals have proved of the utmost service to medicine in the past, and are indispensable for its future progress; and accordingly, while strongly deprecating the infliction of unnecessary pain, it is of opinion that, alike in the interests of man and of animals, it is not desirable to restrict competent persons in the performance of such experiments."

\section{THE BIBLE AND SCIENCE}

The Bible and Science. By T. Lauder Brunton, M.D., D.Sc., F.R.S., \&c. (London: Macmillan and Co., I88r.)

THIS work is in the form of seventeen lectures, which appear to have been delivered before an orthodox audience. Their scope is a wide one, ranging from sketches of ancient Egyptian and Israclitish life to the newest results in biological science. The principal object of the book is professedly that of showing how Darwinism is not antagonistic to Christian belief in general, or to the Masaic account of creation in particular. But although this is the peg, so to speak, on which the course of lectures is made to hang, occasion is taken to devote the main part of the work to rendering in a plain and popular form an epitome of the leading facts of animal and vegetable morphology. This part of the work is admirably done. Indeed we do not know any writings of this nature better calculated to accomplish their object of making science easy to the general reader; and as the spirit is throughout tender, not to say sympathetic, towards traditional beliefs, the book deserves a large circulation among the always increasing class of persons who desire to learn, with a small amount of trouble and without fear of stumbling upon any cloven hoof, what biological science has done, is doing, and is likely to do. In a word, this part of the book, besides being written in a very graceful style, well exemplifies the truth that no writer is so able to serve up to the general public the facts of science in a palatable form as one who is himself a practical worker in the subjects which he expounds. In the interests of scientific education, therefore, we should like to see "The Bible and Science" pass through any number of editions.

Coming now to what is professedly the main object of the work, opinions of course will differ as to the success which has attended Dr. Brunton's efforts. And here it may be observed, first of all, that it is not very clear what the author himself thinks about the deeper topics that underlie his expositions. Apparently addressing an audience of the straitest sect, he judiciously steers clear of all topics save the one immediately before him, i.e. showing that the doctrine of evolution is not incompatible with that of the Mosaic cosmology ; and although this is perhaps more effectively done than by many previous essayists, there is nothing to show that he is not adopting the method of St. Paul, which he commends, who "graduated his instructions to the people whom he was addressing, first giving them milk, and afterwards strong meat" (p. 358). Of course in this there is nothing to find fault. Because a man sticks to a text which does not happen to contain a confession of faith, we have no reason to object that he does not publish his religious opinions; only we think it well to point out that such is here the case, for any reader who is careless or obtuse might fail to perceive the adroitness with which Dr. Brunton steers his discussion among the rocks of dogma. At every point where we feel inclined to ask what our author himself believes, we virtually fall into a dialogue with him such as that with which is told of another eminent man-"What is your own creed?" "The creed of all sensible men." "And what is that?" "Sensible men never say."

But whatever Dr. Brunton's creed may be, his book everywhere breathes with such a genuine, and indeed we may say pathetic, appreciation of the beauty of the biblical writings and the nobility of religious belief, that if he fails to strike a chord which through all changes and chances is ever ready to vibrate deep down in the bass of human nature, we have only to commiserate the reader who has departed so far from the best and the purest of human emotions. Having travelled through Palestine, and knowing his Bible as thoroughly as his science, Dr. Brunton gives us some beautiful little sketches of Bible scenes, lighted up by numberless interesting suggestions derived from modern science, as well as by the glow of a singularly vivid imagination. Take, for instance, the following :-

"Never in my life do I remember a pleasanter moment than when I sat down on one of these, and looked at the scene before me, for this was the realisation of my childhood's dream; this was the spot where Joseph had lived. Yonder might have been the granaries where he received his brothers; here, in the neighbourhood, stood his house, where he returned, weary of his day's work, and was received by his lovely and loving wife Asenath, 